\title{
Engineering Curriculum in Support of Industry 4.0
}

\author{
https://doi.org/10.3991/ijoe.v17i01.17937 \\ Tom A. Eppes ${ }^{(凶)}$, Ivana Milanovic, Reihaneh Jamshidi \\ University of Hartford, Connecticut, USA \\ eppes@hartford.edu \\ Devdas Shetty \\ University of the District of Columbia, Washington D.C., USA
}

\begin{abstract}
The paper discusses how multiphysics simulations and applications are being used to build essential skills in preparation for entry into an Industry 4.0 workforce. In a highly networked and collaborative human/machine cyberspace, some important competencies for engineering graduates include the ability to: (1) explore design options and results easily between suites of software, (2) predict and visualize performance of complex problems in the beginning phase of the design process, and (3) identify and optimize key parameters prior to fabrication. We describe how integrated project- and inquiry-based learning in the context of a simulation environment and across the curriculum is improving student readiness and transition into industry. Our paper offers a template of how to transition into a curriculum that produces newly minted engineers better equipped to engage in complex design. Examples of project assignments, assessment methods, and student work are discussed as well as future plans.
\end{abstract}

Keywords - Multiphysics modeling, simulation, design, engineering, manufacturing

\section{Introduction}

The paper provides a case study of simulations and applications embedded in the undergraduate (UG) engineering curriculum at the University of Hartford (UH). The strategy is early and consistent integration of learning and discovery with modern computational skills. Students transition from (1) courses that teach basic computer skills to (2) discipline-specific courses with multiple simulation assignments and inquirybased learning (IBL), and, finally, (3) specialized professional electives with a focus on advanced modeling and simulation. Our approach fosters a deeper grasp of theoretical cause/effect relationships and cultivates precisely those skills required for the design processes representative of Industry 4.0.

This current study builds on a prior conference publication [1] with the motivation to transform our UG engineering curricula to better equip students to create, optimize, and validate complex designs. This ultimately leads to the successful integration of multiphysics simulations into survey courses and professional electives, and results in better digital engineering preparedness for our graduates. We discuss the skillsets 
needed to successfully perform component and assembly design prior to manufacturing. Specifically, how multiphysics software can be integrated with other tools to analyze, predict, and optimize design performance.

Project- and inquiry-based learning in the context of a simulation environment and across the curriculum are the cornerstones of our strategy. The approach radically changes the concept of student assessment by emphasizing both theoretical concepts and their simulation counterparts. For most of our engineering undergraduates, the process begins in the first year with a graphical communication course such as computeraided design/engineering (CAD/CAE) and engineering computer applications course. Simulations and application building are introduced in the second year with the required engineering courses, and are consistently emphasized throughout the curriculum. Our strategy has the potential to be implemented across a wide range of topical areas within the engineering curricula.

At UH, as well as many other institutions, the first specialized, computational skills are initiated via graphics communications and computer application courses taken by all engineering majors. The objective of the former is to teach students how to create drawing packages that are fully dimensioned and manufacturing tolerances specified. The latter course consists of computer programming, data science, and tools for solving problems (e.g., MATLABß, Microsoft Excel).

For mechanical engineering (ME) majors, another computer-aided design (CAD) course with SOLIDWORKS ${ }^{\circ}$ and ANSYS $®$ is placed in either the second or third year. Until recently, a combination of the aforementioned courses and relevant professional electives featuring finite element analysis (FEA) or computational fluid dynamics (CFD) was the extent of simulation and modeling in the ME curriculum.

Electrical engineering (EE) and computer engineering (CompE) majors encounter simulations throughout their UG tenure. This experience primarily centers on problems that involve one dimension, i.e., time, since many specialties such as signal processing, circuit design, control, and data acquisition do not necessarily require spatial dimensions considerations. However, most graduate without ever learning how to solve problems or create designs in a multidimensional setting.

Professional electives that focus on advanced modeling and simulation are available to all $4^{\text {th }}$ year UGs and Masters' candidates. These courses have proven to be of great value as students benefit from exposure to design concepts/issues outside of their discipline such as heat transfer for EE/CompE and electromagnetic fields for ME.

\section{Background}

\subsection{Educational implications of industry 4.0}

The term Industry 4.0 describes a wide range of technologies and capabilities that make up what is now considered to be the fourth generation of major trends in the global state of manufacturing and services. A well supported definition of Industry 4.0 is presented by Hermann et. al. [2] as: 'Industry 4.0 is a collective term for technologies and concepts of value chain organization. Within the modular structured Smart Factories 
of Industry 4.0, Cyber-Physical Systems (CPS) monitor physical processes, create a virtual copy of the physical world and make decentralized decisions. Over the IoT (Internet of Things), CPS communicate and cooperate with each other and humans in real time. Via the IoS (Internet of Services), both internal and cross-organizational services are offered and utilized by participants of the value chain.' The implementation of CPS combined with IoT can provide intelligent systems capable of self-learning which represents the core of Industry 4.0 [3]. As part of intelligent system, machine learning (ML) is implemented in various manufacturing fields with the goal of extracting knowledge out of existing data [4]. The new knowledge supports the process of making predictions or decision making in a manufacturing system [5]. The three previous revolutions transpired over the past 250 years and are characterized by (1) mechanization via steam and water power, (2) interchangeable parts and mass production with electrically-powered assembly lines, and (3) integration of computers for automated process control. For Industry 4.0, some of the key aspects involve: (1) artificial intelligence and big data integrated into machine learning, prediction, and decision-making, (2) continued expansion of software tools and applications in a highly networked environment, (3) new/advanced materials and fabrication processes, and (4) humans/machines working in a virtual and collaborative setting.

It is apparent that a major shift is underway, and the key question for engineering educators is: are our students being properly prepared? A thorough literature review of Industry 4.0 and strategic roadmap by Ghobakhloo [6] found twelve key design principles and technology trends of Industry 4.0. Internet of things, Virtualization, and Product Personalization are examples of these design principles. This digital transformation is described by Richert, Shehadeh, Willicks, and Jeschke [7] as a challenge of learning to solve complex, multidisciplinary problems within changing teams in virtual worlds. Jeganathan, Khan, Raju, and Narayanasamy [8] went so far as to propose a single curriculum framework specifically for Industry 4.0. It is unclear how most engineering programs plan to address these changing educational requirements. Perhaps as augmented reality technology finds its way into institutional settings, more experiential results will be reported. Thus far, UH has taken the path of evolutionary change by increasing the emphasis on simulation-based learning and multidisciplinary problem solving in UG course bundles.

\subsection{Software platforms used in prototype design}

In the design process of manufactured products, there has been for several decades an expanding and evolving role played by specialized software platforms in the creation, analysis, and evaluation of prototype alternatives. However, there are relatively few examples [9-11] making a case for exploring engineering topics using modern software tools, and they mostly deal with individual courses. It should be noted that although Bruhl, Gash, Freidenberg, Conley, and Moody [11] advocate for integrating finite element analysis (FEA) practice throughout the civil engineering and ME curricula, we could not find any institutions where this has been implemented.

One question that often comes up is: 'are students truly capable to use modern cyber devices and which ones are most prevalent?' Motyl, Boronio, Uberti, Speranza, and 
Filippi [12] performed a survey and found that the two largest groups are smartphones and laptop/desktop computers. They suggest that students are quite well prepared for the integration of simulation and modeling into the curriculum.

To address the above educational skill requirement at UH, the authors first incorporated multiphysics simulations into the curriculum ten years ago. Initially, there were concerns about how quickly and effectively undergraduates in particular could learn to use the complex user interfaces and understand underlying numerical methods resident in the software. A detailed discussion of what turned out to be a rather successful evolution of simulation content into our UG curriculum can be found in Ref. [13].

\section{$3 \quad$ Simulation and Design Integration}

Consider, for example, the task of creating a design for an electro-mechanical device consisting of two assemblies. The first is a physical area where solids/fluids interact with a sensor and/or actuator such as a piezo-electric element or a motorized mixer. The second assembly is an electronic circuit that receives sensor outputs and/or generates a driver signal for an actuator located in the prior assembly. In total, the design consists of two components, one mechanical and the other electronic, that must be interfaced and work in tandem. Let's explore the primary design steps and software tools that might be used to develop a fully functioning device.

For our purposes, four software platforms are employed: (1) SOLIDWORKS, (2) COMSOL Multiphysics ${ }^{\circledR}$, (3) OrCAD $®$ PSpice $\AA$, and (4) Abaqus FEA. These platforms can be interfaced to one another via import/export of files or synchronized so that any change made in one is automatically propagated to the others. To illustrate how a design process may unfold, Fig. 1 shows the four platforms linked into a sequence of activities and interactions to be performed prior to producing a working prototype.

It normally begins with a set of product requirements or objectives that either relate directly to the mechanical and/or electrical performance of the device or may designate expectations in the areas of reliability, durability, manufacturing, or packaging. The first step then is to create a suitable mechanical structure in the form of a 3D drawing package within SOLIDWORKS ${ }^{\circ}$. This structure may contain fluids, channels, and solid domains including parts such as electrodes, motors, or interconnects. Once created this file should provide a complete set of dimensions, tolerances, and material selections for the device. In the early stages, multiple independent designs will likely be analyzed in parallel until it becomes clear which one is the best candidate.

The next step is to prepare a modeling file within COMSOL into which the drawing file can be imported. Prior to the import, the model should reflect the number of space dimensions (e.g., 2D, 2D-axisymmetric, or 3D) and represent the most significant parameters as variables to facilitate in-depth analysis. The relevant physics should also be identified such as heat transfer, fluid flow, electric circuits, etc. It is essential that all of the governing equations are included with a complete set of boundary conditions and excitations. 


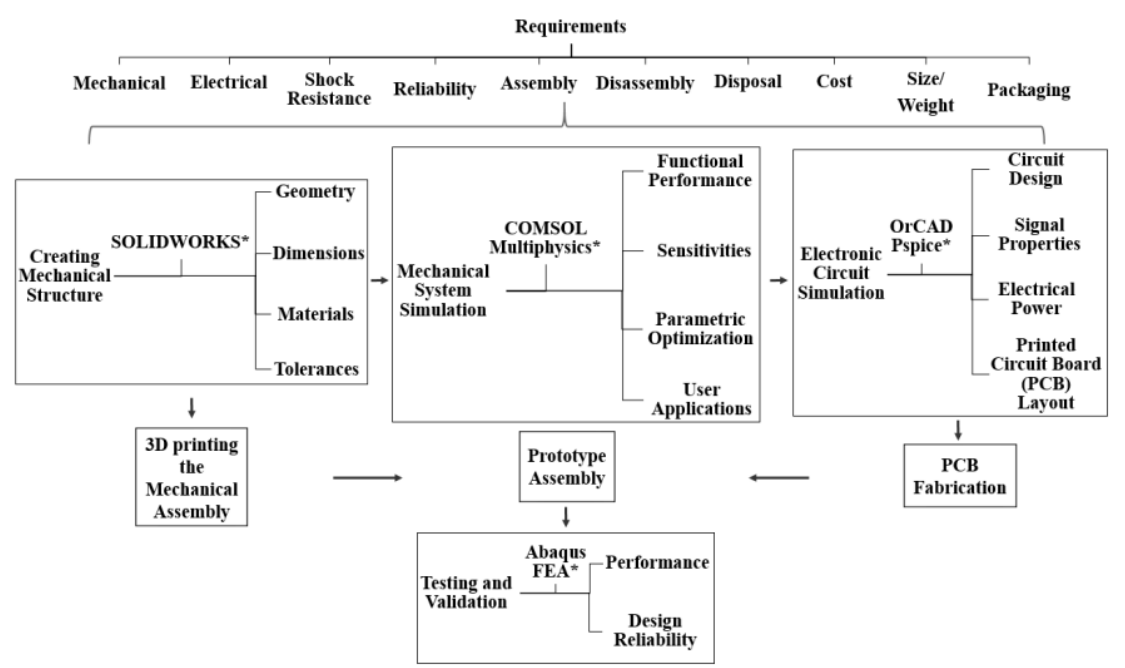

Fig. 1. Electro-mechanical assembly design process and key software platforms

The drawing file can now be imported, and the materials (with properties) incorporated and linked to the physical domains within the device. Prior to performing a study, an appropriate mesh or finite element structure is created which can take much time and effort depending on the complexity of the device physics. After a finished study is obtained, a wide range of plots and tables can be post-processed and examined. Some common types of analyses that may produce insightful results are: parametric sweeps, material sweeps, internal probe (or cuts) plots along specific contours, and parametric sensitivities/optimizations.

Here is where the design process becomes interdisciplinary. Assume that the excitation function is to be replaced by an actual electronic circuit. In Fig. 1, this can be accomplished using OrCAD® PSpice® that can simulate the performance of an electronic circuit. Once the design is deemed acceptable, the file can be imported into COMSOL® and used as the excitation source within the model.

Some modifications to the physics and boundary conditions may be needed in the changeover. Additional studies will likely be worthwhile to further refine the overall electro-mechanical design. In most cases, the design process is highly iterative and requires a lot of re-thinking and back-and-forth across the various software platforms to produce a worthwhile outcome.

Once a successful design is identified for both the mechanical and electrical assemblies, the next stage is to fabricate a physical prototype. In this example, the SOLIDWORKS $®$ file would be targeted by a $3 \mathrm{D}$ printer to produce the mechanical assembly. A capture feature in PSpice ${ }^{\circledR}$ can produce a printed circuit board layout for fabrication and population with electrical components. Following final integration and assembly, a working prototype is ready for testing and validation. It is also imperative to embed design reliability tests in the validation process. Abaqus Unified FEA can be employed to test the electromechanical system design under the applicable loads, and employ a fatigue failure test to estimate the lifetime of the device. A comprehensive 
failure mode effect analysis (FMEA) may also be conducted to identify other potential causes of failure for consideration in the reliability tests. The entire design process just discussed could have been performed in a networked computing environment involving multiple individuals/teams, each located in different places, facilities, and organizations. This is the present and future of engineering design that graduates will encounter.

\section{$4 \quad$ Multiphysics and Simulation Courses}

\subsection{Required courses for ME undergraduates}

Given the previous design example, this is why and how in the ME program we evolved a strong emphasis on modeling and simulation. For many years, we have been hearing from students that basic computational skills courses have been placed far apart from the professional electives. On our side of the aisle, we saw benefits of having descriptive geometry topics before a string of mechanics courses. We also understood the necessity of a computer application course with an emphasis on problem solving tools such as MATLAB® and MS Excel. However, the follow-up survey courses did not necessarily incorporate modern computational tools. Most capstone projects are sourced from and sponsored by industry and have at least one component that requires simulations. We needed to bridge this gap.

We now use examples of solid mechanics and thermo-fluids courses in the ME curriculum to illustrate discipline-specific courses with multiple simulation assignments and an embedded inquiry-based learning (IBL). The solid mechanics course is a lab based materials testing course in the second year, and the thermo-fluids courses consist of thermodynamics in the second year, and fluid mechanics and heat transfer in the third year [13]. Abaqus FEA is chosen as the solid mechanics software for its vast demand in the materials and manufacturing industry, as well as its intuitive post processing environment. The choice of COMSOL for thermo-fluids is the result of the authors' prior success with a graduate multiphysics modeling course. Our initial objective was to have software tools that provided sufficient disciplinary breadth to address a range of engineering problems.

In the materials testing lab course, each student group is assigned a project to simulate one of the materials testing procedures previously done in the lab. Topics covered (1) tensile testing of ductile materials, (2) tensile testing of brittle materials, (3) torsional testing of ductile materials, and (4) torsional testing of brittle materials. Virtual test samples have the same specifications as their experimental counterparts. The project design is based upon two teaching strategies. The first strategy is team learning. Students form groups of four as the simulation project collaborators. The role of instructor is mentoring the students to facilitate learning, rather than controlling the learning path. The second strategy is scaffolding, which refers to a variety of instructional techniques applied to progressively enhance students' understanding, and move them towards greater independence during the learning process. The scaffolding strategy implemented in the materials testing simulation is breaking down the assignment into smaller steps, from the sketch, to visualization, and checking on students' progress at the end 
of each task. Upon facing difficulty students seek help from other members of the project team, or the instructor.

As part of their assignment, students explain the similarities between the simulation results and experimental data, as well as input requirements allowing acceptable accuracy. They also are expected to describe the differences and explore the potential sources of variations. This is meant to promote students' analytical thinking by connecting multiple learning approaches: theory, experiment and simulation. Figure 2 demonstrates an example of such comparison between simulation and experiment. Analysis of the results by students are presented in Ref. [14].
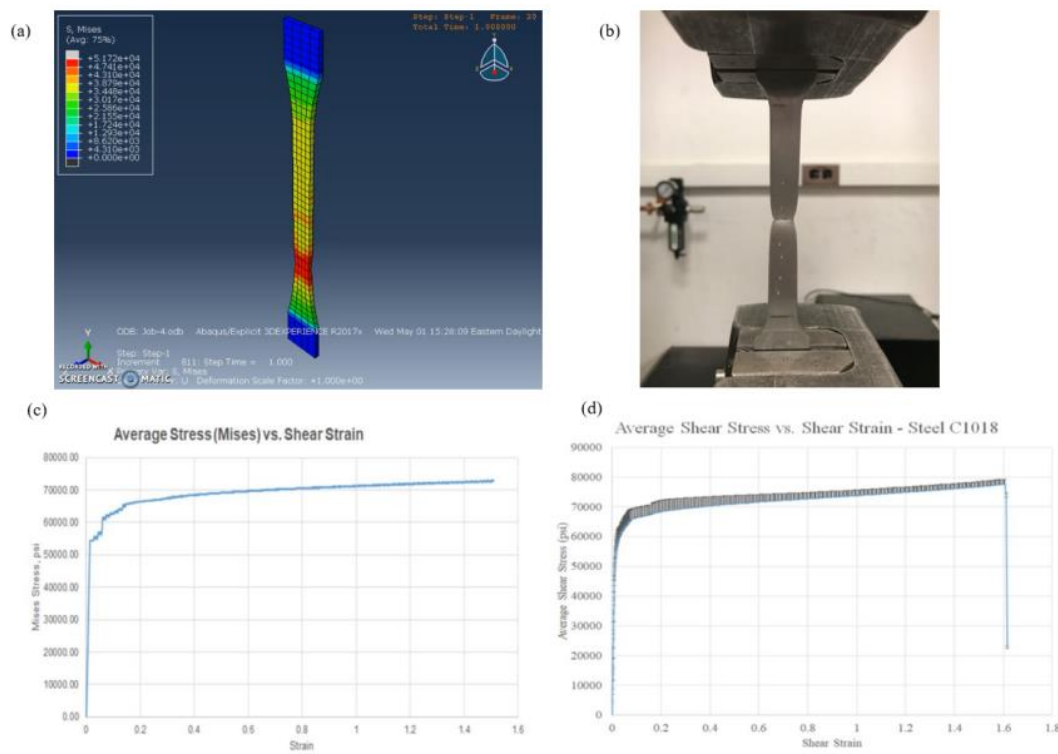

Fig. 2.

The thermodynamics course has four simulation assignments that introduce students to the software. The use of the software in the final project is limited due to the students' inexperience in simulations. Fluid mechanics and heat transfer contain ten simulations along with an embedded IBL as well as application building. Each of these courses is based upon four strategic learning pillars [13]. The first pillar is to employ exciting and relevant images, animations, and movies, both inside and outside of the classroom. Images help students stay engaged, enabling them to visualize and understand effects that can be hard to see or imagine. The second pillar is an enhanced online environment that includes not only lecture materials and practice problems, but also visuals, and outside resources like blog posts and videos. The augmented online learning space provides students with access to better (and more) information which helps lighten the load on faculty during office hours. The third pillar is the 'new homework,' simulation and application assignments. Simulations start out simple, but gain complexity as students become more familiar with the software tool. Customized grading rubrics include a section for IBL with similarly increasing levels of difficulty as the course progresses. 
The fourth pillar is faculty mentoring and effective reference materials that help move students from structured tasks (guided simulation assignments) to the unstructured IBL.

In one project, a user application that employs the underlying simulation must be developed. Figure 3 shows an example of one student's work that was featured in engineering.com and comsol.com. It contains an area where the user can simulate different fluids and/or values for such parameters as size and location of the flow over a cylinder and the distance between the surrounding walls. The graphical area has a tabbed interface that can show either the geometry, velocity field, or fluid pressure.

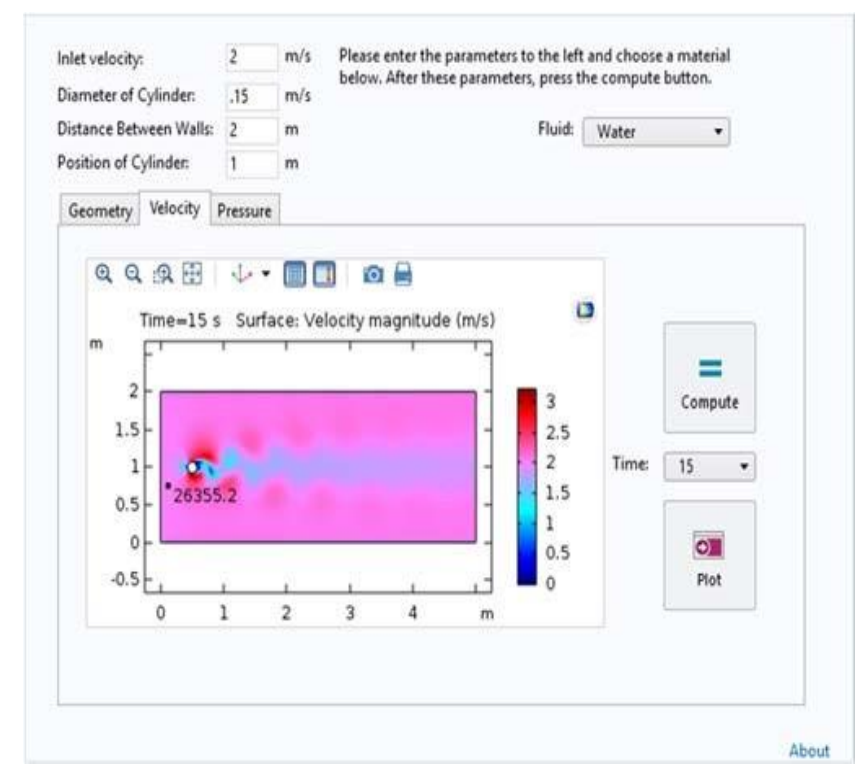

Fig. 3. Application interface for particle flow past a cylinder

\subsection{Required courses for EE / CompE undergraduates}

The EE and CompE curricula have a long history of embedded simulations dispersed across the discipline specific courses. The process begins with a four-course sequence focused on circuit and electronic analysis/design taken in the $2^{\text {nd }}$ and $3^{\text {rd }}$ years. Students learn how to use PSpice ${ }^{\circledR}$ to create time and frequency analyses of circuits that contain both active and passive components. In laboratory sections, student designs are (1) simulated prior to being (2) breadboarded, and (3) measured to compare with actual results with those predicted. Physical printed circuit board layouts and fabrication are not included in this sequence; however, students are encouraged to learn this feature outside of class.

During the $3^{\text {rd }}$ and $4^{\text {th }}$ year, additional courses introduce other software platforms such as National Instruments LabVIEW $®$ and MatLAB Simulink®. These platforms concentrate on time domain data acquisition, signal processing and automation/control. Programming and configuration skills are learned that enable both digital and analog 
signals to be processed as either inputs or outputs. CompE has an emphasis on digital processing, so students are required to take courses that use very high-level description language (VHDL) to design, simulate, build and confirm the function of a variety of programmable devices.

The challenge for EE and CompE was how to broaden the exposure to include multiple dimensions of space and time. With the traditional emphasis on the time domain, graduates were not exposed to heat transfer, solid mechanics, or even devices that rely on electro-, magneto-, acousto- or piezo- effects. This became part of our motivation for the development of the multiphysics course described below, which is open to all engineering majors.

\subsection{Professional electives}

For MEs, three professional elective courses are offered in the fourth year that extend and deepen the simulation experience. Convective Heat and Mass Transfer contains ten simulation assignments. A second elective, Finite Element Analysis, addresses the analysis of 2D and 3D physical structures. In addition, a Computational ME concentration (Comp ME) was recently established for those UGs who wish to focus in this area.

For EEs and CompEs, two graduate courses may be taken by $4^{\text {th }}$ year students: System Design \& Implementation, followed by Simulation \& Rapid Prototyping. Both courses concentrate on the design of complex analog and digital circuits that are first simulated in PSpice ${ }^{\circledR}$ and then fabricated on custom printed circuit boards with component layouts created using the Capture feature. A multi-week culminating project integrates and demonstrates the full set of skills learned.

The most advanced content or simulation skill development is Multidisciplinary Modeling, which is available to all fourth-year engineering majors as well as graduate students. A detailed discussion of the content, examples, and assessment can be found in Ref. [15]. Complementing the lecture portion of the course, seven simulation assignments as well as a multi-week end-of-semester IBL project are required. An example of one simulation that is particularly valuable for EE majors involves analyzing the radar cross-section produced when an incident plane wave strikes a $2 \mathrm{D}$ metallic surface. Figure 4 shows the total electric field in polar coordinates in the form of a colorized surface plot. Students are expected to investigate how the shape of the object affects the reflected electric field as the angle of incidence changes.

A second and more in-depth multidisciplinary modeling course is being contemplated as a follow on to the above offering. It would include a robust exposure to sensitivity analysis and optimization for models with multiple sets of coupled physics and/or nonlinear material properties. 


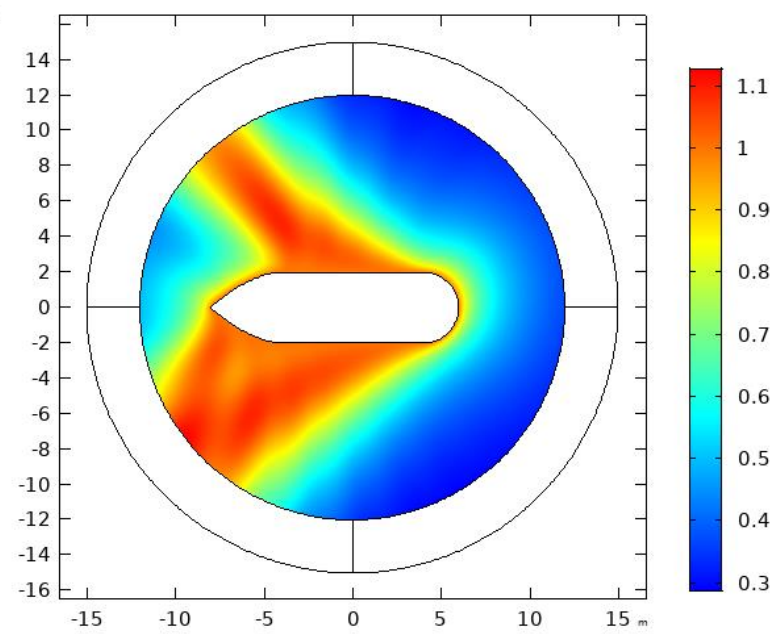

Fig. 4. Reflected electric field (V/m) from an incident plane wave

\section{$5 \quad$ Assessment of Student Work}

Assessment of student work varies somewhat in each of the courses; however, the emphasis is consistently on the technical reports that document the simulation work. As an example, here is how assessment is performed in the professional elective, Multidisciplinary Modeling. Each technical report is graded using a Report Grading Criteria that lists/describes the specific elements to be included and addressed. Students normally start with an exported raw report directly from COMSOL and modify it to suit their purposes. This raw report contains most of the tables and figures needed; however, many are unnecessary and should be removed. Students write a narrative in each section that discusses the illustrations and what is being presented. All tables and figures must be fully captioned and referenced.

While much of the modeling work is guided by step-by-step instruction, each assignment has an IBL component in which students must figure out what to do on their own. The IBL component requires that they perform some research and exploration to accomplish this task. In the Report Grading Criteria, the IBL requirement is described in sufficient detail with clear expectations. Table 1 is a sample Report Grading Criteria for one of the assignments that shows how points are distributed and awarded. In addition to the reports, some weight (typically 10\%) is placed on an online quiz associated with each assignment. 
Table 1. Sample Report Grading Criteria

\begin{tabular}{|l|c|}
\hline \multicolumn{1}{|c|}{ Area } & Points \\
\hline Custom cover page: Name, report title, report number, \& thumbnail. & 15 \\
\hline $\begin{array}{l}\text { Structure: Export brief report, add 'Conclusions' at end, modify 'Table of Contents' to include } \\
\text { 'Conclusions', \& create a 'List of Figures'. }\end{array}$ & 20 \\
\hline $\begin{array}{l}\text { Content: Remove all tables \& figures not relevant, include the following: geometry, mesh, fig- } \\
\text { ures in instructions, pressure contour plot (mmHg). Other figures are: specified below. Figs } \\
\text { must be numbered consecutively, have relevant captions, legends with max/min values \& units. }\end{array}$ & 40 \\
\hline $\begin{array}{l}\text { Inquiry-Based Learning (IBL): Create an application for an end user that is interested in re- } \\
\text { sults only. Provide a snapshot of your application with a time continuation parameter, relative } \\
\text { pressure amplitude. Include a geometry button, mesh button, plot of velocity magnitudes, pres- } \\
\text { sure contours, and surface displacement. Advanced students only: Surprise me with something } \\
\text { new that I have not seen in your work before. }\end{array}$ & 25 \\
\hline Total Possible Points & 100 \\
\hline
\end{tabular}

After eight of the fifteen weeks, all of the modeling assignments will have been completed, and an end-of-semester design project begins. The authors have tried several approaches: (1) all students work on the same project, (2) students select a project from a list, or (3) students propose a project. In our view, allowing students to submit a proposed statement of work for a project of interest works best. A formal oral presentation (and a technical report for graduate students) is required during the final week. The overall grade is a weighted average of the modeling reports, quizzes, and end-of-semester report/presentation. Table 2 shows how the course grades are computed for both graduate and UG students.

Table 2. Overall course grade

\begin{tabular}{|l|c|c|}
\hline \multicolumn{1}{|c|}{ Assignment } & Undergraduate & Graduate \\
\hline Weekly Technical Reports (7 simulations) & 70 & 70 \\
\hline Weekly Quizzes (7 simulations) & 10 & 10 \\
\hline End-of-Semester IBL Project & & \\
\hline Technical Report & - & 10 \\
\hline Oral Presentation & 20 & 10 \\
\hline Total Points & 100 & 100 \\
\hline
\end{tabular}

\section{Conclusion}

This paper discusses improvement of undergraduate student readiness for entry level careers in the context of the Industry 4.0 paradigm. Our strategy is the early and consistent integration of learning and discovery with modern computational skills. Students transition from (1) courses that teach basic computer skills to (2) discipline-specific survey courses with multiple simulation assignments and embedded inquiry-based learning, and, finally, (3) specialized professional electives that focus on advanced modeling and simulation. Graduates are better prepared to engage in digital product design having been exposed to the process of using complex and integrated industryclass software platforms such as AutoCAD®, SOLIDWORKS®, Abaqus FEA, COMSOL Mutiphysics ${ }^{\circledR}$, and OrCAD® PSpice ${ }^{\circledR}$. Feedback over several years from 
graduates regarding their readiness has been quite positive and plans are in place to continue the expansion of this initiative.

\section{$7 \quad$ References}

[1] T. Eppes, I. Milanovic and D. Shetty, "The Future of Things: Simulations and Next Generation Manufacturing," 2020 IEEE Global Engineering Education Conference (EDUCON), Porto, Portugal, 2020, pp. 442-446, https://doi.org/10.1109/educon45650.2020. $\underline{9125282}$

[2] M. Hermann, T. Pentek and B. Otto, "Design Principles for Industrie 4.0 Scenarios," 2016 49th Hawaii International Conference on System Sciences (HICSS), Koloa, HI, 2016, pp. 3928-3937, https://doi.org/10.1109/hicss.2016.488

[3] B. Nikolic, J. Ignjatic, N. Suzic, B. Stevanov, and A. Rikalovic, "Predictive Manufacturing Systems in Industry 4.0: Trends, Benefits and Challenges," Proceedings of the 28th DAAAM International Symposium, 2017, pp. 796-802. https://doi.org/10.2507/28th.daaam. proceedings. 112

[4] S. Sumathi and L. A. Kumar, "Computational intelligence paradigms for optimization problems using MATLAB ${ }^{\circledR} / \mathrm{SIMULINK}{ }^{\circledR}, ” \quad C R C$ Press, 2018. https://doi.org/10.1201/ b19134

[5] T. Wuest, D. Weimer, C. Irgens, and K.-D. Thoben, "Machine learning in manufacturing: advantages, challenges, and applications," Production \& Manufacturing Research, vol. 4, no. 1, pp. 23-45, 2016. https://doi.org/10.1080/21693277.2016.1192517

[6] M. Ghobakhloo, "The future of manufacturing industry: a strategic roadmap toward Industry 4.0," Journal of Manufacturing Technology Management, vol. 29, no. 6, pp. 910-936, 2018. https://doi.org/10.1108/jmtm-02-2018-0057

[7] A. Richert, M. Shehadeh, F. Willicks, and S. Jeschke, "Digital transformation of engineering education-empirical insights from virtual worlds and human-robot-collaboration," International Journal of Engineering Pedagogy, vol. 6, no. 4, pp. 23-29, 2016. https://doi.org/10. 3991/ijep.v6i4.6023

[8] L. Jeganathan, A. N. Khan, J. Kannan Raju and S. Narayanasamy, "On a Frame Work of Curriculum for Engineering Education 4.0," 2018 World Engineering Education Forum Global Engineering Deans Council (WEEF-GEDC), Albuquerque, NM, USA, 2018, pp. 16, https://doi.org/10.1109/weef-gedc.2018.8629704

[9] W. Reffeor, "Using FEA as a Pedagogical Tool for Teaching Machine Component Design," ASEE Annual Conference and Exposition, 2018, pp. 24-27. https://doi.org/10.18260/1-2-$\underline{31205}$

[10] J. M. Papadopoulos, C. Papadopoulos, and V. C. Prantil, "A Philosophy of Integrating FEA Practice throughout the Undergraduate CE/ME Curriculum," ASEE Annual Conference and Exposition, 2011, pp. 1-14. https://doi.org/10.18260/1-2--17365

[11] J. C. Bruhl, A. Freidenberg, R. Gash, C. Conley, and P. Moody, "Helping Students Learn Engineering Mechanics Concepts Through Integration of Simulation Software in Undergraduate Courses," ASEE Annual Conference and Exposition, 2018, pp. 1-16. https://doi.org/10.18260/1-2--30573

[12] B. Motyl, G. Baronio, S. Uberti, D. Speranza, and S. Filippi, "How will change the future engineers' skills in the Industry 4.0 framework? A questionnaire survey," Procedia Manufacturing, vol. 11, pp. 1501-1509, 2017. https://doi.org/10.1016/j.promfg.2017.07.282

[13] I. Milanovic, T. Eppes, and K. Wright, "Simulation-Based Approach to Science, Technology, Engineering, and Math Challenges," Proceedings of the ASME-JSME-KSME 2019 8th 
Joint Fluids Engineering Conference. Volume 1: Fluid Mechanics. San Francisco, California, USA. July 28-August 1, 2019. V001T01 A045. ASME. https://doi.org/10.1115/AJKFluids2019-4864. https://doi.org/10.1115/ajkfluids2019-5550e

[14] R. Jamshidi and I. Milanovic, "Adding a Simulation Module to a Primarily Experimental Mechanical Engineering Course," 2020 ASEE Virtual Annual Conference, 2020, pp. 1-9, https://peer.asee.org/34091. https://doi.org/10.18260/1-2--34091

[15] T. A. Eppes, I. Milanovic, and K. Wright, "Improving Student Readiness for Inquiry-Based Learning: An Engineering Case Study," International Journal of Online and Biomedical Engineering, vol. 16, no. 01, pp. 4-17, 2020. https://doi.org/10.3991/ijoe.v16i01.12051

\section{Authors}

Tom A. Eppes is a professor of electrical \& computer engineering at the University of Hartford. His area of expertise is multiphysics modeling and photonics. Dr. Eppes is a contributing author for more than 80 journal articles, conference papers, technical reports, and software releases. He is a member of the Institute of Electrical \& Electronics Engineers (IEEE) and American Society for Engineering Education (ASEE). Email: eppes@ hartford.edu

Ivana Milanovic is a professor of mechanical engineering at the University of Hartford with ongoing research programs in vortical flows, computational fluid dynamics, multiphysics modeling, and inquiry-based learning. She is a contributing author for more than 100 journal articles, NASA reports, conference papers, and software releases. Dr. Milanovic is an American Society of Mechanical Engineers (ASME) Fellow, and a member of the American Institute of Aeronautics and Astronautics (AIAA) and the American Society for Engineering Education (ASEE).

Reihaneh Jamshidi is an assistant professor of mechanical engineering at the University of Hartford. She specializes in Materials and Manufacturing. Her technical research interests include design, manufacturing, characterization, and mechanics of soft materials and structures.

Devdas Shetty is Dean of the School of Engineering and Applied Sciences at the University of Washington, D.C. He specializes in mechatronics and advanced manufacturing processes.

Article submitted 2020-08-21. Resubmitted 2020-10-12. Final acceptance 2020-10-13. Final version published as submitted by the authors. 